\title{
T-DNA Tagging of Nodulation- and Root-Related Genes in Lotus japonicus: Expression Patterns and Potential for Promoter Trapping and Insertional Mutagenesis
}

\author{
Luca Martirani, ${ }^{1}$ Jiri Stiller, ${ }^{2}$ Rossana Mirabella, ${ }^{1}$ Flora Alfano, ${ }^{1}$ Alessandro Lamberti, ${ }^{1}$ \\ Simona E. Radutoiu, ${ }^{2}$ Maurizio laccarino, ${ }^{1}$ Peter M. Gresshoff, ${ }^{2}$ and Maurizio Chiurazzi ${ }^{1}$ \\ ${ }^{1}$ International Institute of Genetics and Biophysics, Via Marconi 12, 80125, Napoli, Italy; ${ }^{2}$ Plant Molecular \\ Genetics, Center for Legume Research, The University of Tennessee, Knoxville 37901-1071, U.S.A. \\ Accepted 15 December 1998.
}

\begin{abstract}
High-efficiency transformation of the autogamous diploid legume Lotus japonicus by means of Agrobacterium rhizogenes was used to develop plant lines expressing a promoter-less gusA gene in a nodulation- or lateral rootassociated manner. The approach exploits the putatively preferential integration of T-DNA into actively transcribed regions, thereby providing an enrichment for gene tagging events associated with the quickly assayable activation of a gusA promoter-less construct. Taking advantage of this enrichment and selection strategy, a T-DNA tagging program was initiated and screening for $\beta$-glucuronidase (GUS) activity was performed on root clones isolated after transformation with a gusA-promoter-less binary vector. The aim of this approach is the identification of genes involved in nodule formation induced by Mesorhizobium loti, lateral root organogenesis, and the eventual isolation of corresponding mutants. A large collection (220) of GUSpositive transformants showing a variety of expression patterns in different regions of roots and nodules was obtained; a preliminary molecular characterization of these plants is presented.
\end{abstract}

Additional keyword: symbiosis.

The understanding of the Rhizobium spp.-legume symbiosis has expanded considerably with respect to the knowledge of the chemical signals perceived and produced by the bacterial partner (Long 1996). The plant role in symbiosis has been difficult to analyze, because of complex genetics, long generation times, complex genomes, and relatively inefficient gene transfer technologies with the major large-seeded legumes, such as bean, soybean, and pea. Many nodulin genes from several legumes have been cloned; the analysis of their DNA sequences as well as their patterns of expression during nod-

Corresponding author: Maurizio Chiurazzi; Telephone: 39-81-725 7223; Fax: 39-081-593 6123; E-mail: chiurazzi@iigbna.iigb.na.cnr.it

Present address of L. Martirani: Università Federico II, Dipartimento di Fisiologia generale e Ambientale, Sezione di Microbiologia, Via Mezzocannone 16, 80134, Napoli, Italy.

Present address of M. Iaccarino: UNESCO, 7 Place de Fontenoy, 75352, Paris, France. ule formation has revealed interesting characteristics of the deduced proteins. Nevertheless, the exact function of most nodulins, such as ENOD40, ENOD2, and ENOD12, remains unknown at present. Similarly, many plant mutations have been isolated and characterized, but the corresponding gene sequences still await map-based cloning (see Gresshoff 1993; Kolchinsky et al. 1997).

Gene tagging utilizes the insertion of a defined piece of DNA in the vicinity of a target gene and is a powerful approach for a rapid analysis of gene expression and of the phenotypes resulting from disruption of the mutagenized genes. Not all tagging events result in a mutant phenotype. The potential of Agrobacterium spp. T-DNA as an insertion tag was demonstrated with Arabidopsis thaliana (Feldman 1991); however, this plant is unable to form symbioses with either rhizobial or mycorrhizal partners. Among legume species, the diploid plant Lotus japonicus has been developed as a model plant (Handberg and Stougaard 1992; Jiang and Gresshoff 1997; Thykjaer et al. 1995; Szczyglowski et al. 1997) to overcome experimental shortcomings associated with other species. Protocols for A. tumefaciens and A. rhizogenes transformation-regeneration procedures in L. japonicus have been published (Handberg and Stougaard 1992; Stiller et al. 1997; Quaedvlieg et al. 1998) and a detailed analysis of root infection and nodule ontogeny has been recently reported (Szczyglowski et al. 1998), making this plant ideal for a TDNA tagging program aimed at the identification of genes involved in nodule development and function as well as the isolation of related root morphogenesis mutants.

A. rhizogenes is responsible for the induction of the hairy root disease of dicotyledonous plants. A small segment of DNA (T-DNA) from a large root-inducing plasmid (Ri plasmid) is transferred by the bacterium to infected plant cells, controlling their growth and their differentiation into hairy roots (Chilton et al. 1982). The adventitious roots arising from the wound site can be cultured in vitro in media devoid of plant hormones, where they grow very rapidly with a characteristic highly branched and nongeotropic pattern (Chilton et al. 1982). Each root arising on the original infection site is thought to be an independent clone with a unique T-DNA integration (David et al. 1984). Exploitation of a promoter-less gusA reporter gene linked to the T-DNA border provides a sensitive, in vitro 
visualization and selection procedure for the identification of transcriptional fusions expressed in various tissues of transformed plants (Topping et al. 1994; Jefferson 1987).

We describe here the utilization of a new A. rhizogenesbased root transformation system in L. japonicus. A comparison with the hypocotyl transformation procedure indicates an enrichment for transformants showing various patterns of $\beta$ glucuronidase (GUS) expression in different root regions; this is probably related to the preferential integration of T-DNA into actively transcribed regions. On the basis of this proce- dure, a fast and reliable experimental scheme for T-DNA tagging was established. A large collection of GUS-positive root explants representing independent loci of integration was obtained. These clones were further characterized by analysis of the GUS activity after inoculation of regenerant plants with Mesorhizobium loti, revealing distinctive patterns of GUS expression in root and nodular tissues. We believe that the tagged lines will be of value to the further analysis of tissueand organ-specific gene expression during nodulation and lateral root development.
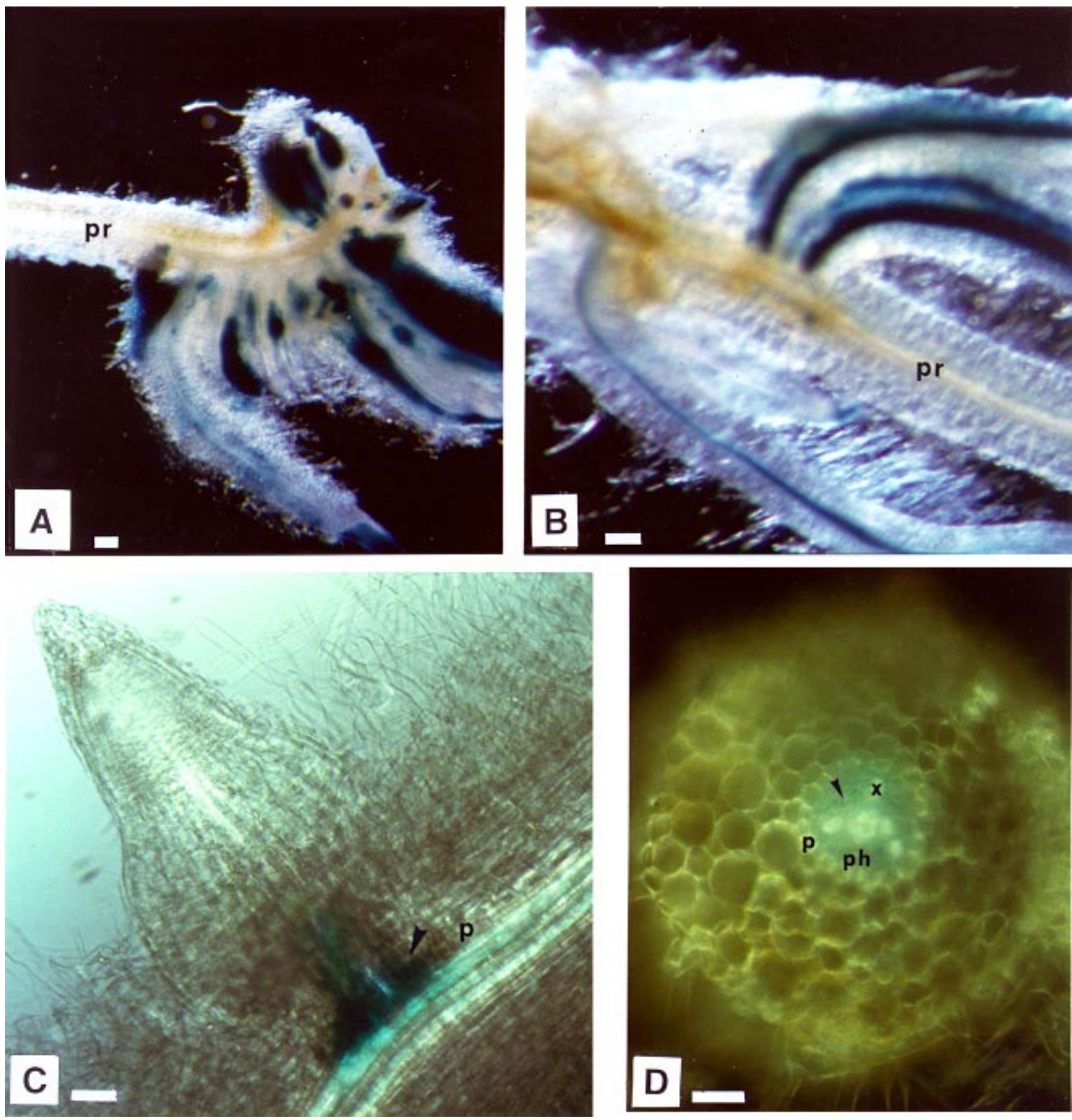

Fig. 1. Histochemical analysis of GUS ( $\beta$-glucuronidase) activity in transgenic Lotus japonicus root explants transformed with the (A and B) p35S-gusAint and (C and D) pENOD4O(2)-gusA-int. A, Callus with emerging transgenic roots at 10 days from the infection after treatment with 5-bromo-4-chloro3-indolyl- $\beta$-D-glucuronic acid (X-gluc). B, Transgenic roots differentiating through direct organogenesis on the primary root. C, GUS activity in the dividing pericycle cells of the root stele in the region of emergence of a secondary root (arrowhead). D, Cross section showing GUS activity in the cells between the xylem and phloem (arrowhead). Abbreviations: p, pericycle; ph,phloem; pr, primary root; $x$, xylem. 


\section{RESULTS}

\section{Transformation procedures and efficiencies.}

Transformed roots were generated by wound site infection with A. rhizogenes on the elongation zone of primary roots of L. japonicus ecotype Gifu. The infection was performed at day 6 after agar plate germination when young plants with only unfolded cotyledons were present. As observed with hypocotyl and epicotyl infection for agropine strains on different legumes, visible callogenesis preceded root formation (Quandt et al. 1993). The transformed phenotype was observed in 60 to $70 \%$ of the infected plants. In uninfected wound sites, microcallus formation was never seen and single roots developed only occasionally. Their morphology was clearly distinct from those developing after $A$. rhizogenes transformation.

To verify the root transformation via co-transfer and expression of the gus A-intron reporter gene (hereafter called gus Aint), A. tumefaciens MSU440 carrying the pRiA4 was equipped with binary plant vector p35S-gusA-int. Analysis of transformed roots was performed on composite plants that consisted of a transgenic root system and wild-type shoot (Stougaard et al. 1986; Beach and Gresshoff 1988). Blue staining of the roots indicated the expression of the GUS enzyme (Fig. 1A). Microscopic examination of the wound sites also showed transgenic roots arising by direct organogenesis from the primary root near the wound site (Fig. 1B). GUS staining revealed activity in $75 \%$ of single roots tested, indicating a high frequency of co-transformation of the gusA-int and pRi-born T-DNAs. Intense GUS activity was observed in the root meristem and the central vascular cylinder; this pattern of expression was maintained in transgenic root explants grown in axenic cultures.

\section{Are hairy roots suitable for nodulation gene studies?}

To ascertain whether a visual screen based on GUS expression in transgenic roots of $L$. japonicus would be able to detect gene expression of nodulation-related genes, we conducted a pre-experiment with nodulin promoters linked to the gusA reporter gene. Constructs involved the gusA-int gene to eliminate the possibility of positive signals based on expression from free-living but co-inhabiting agrobacteria. In transgenic root explants a disturbed hormone balance caused by $A$. rhizogenes rol gene expression and the absence of the shootderived factors may affect the expression of nodulin genes. This is especially critical, since nodulation initiation as well as lateral root formation are likely to be elicited by a change of the endogenous phytohormone(s) levels (Hirsch 1992). However, on the developmental level we have not been able to detect major differences in the lateral root phenotypes of "rhizogenes" roots in L. japonicus. In order to test the activity of specific nodulin promoters in this explant system, we have transformed $L$. japonicus roots with three different T-DNA constructs carrying the soybean promoters of the ENOD4O(2), $\operatorname{ENOD2}(B$,$) and leghemoglobin (l b c 3)$ genes fused to the gusA-int reporter.

Transformed roots were obtained and grown on MS/2 me-

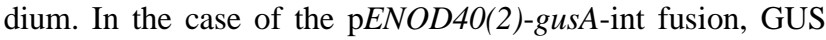
staining was revealed in $83 \%$ of analyzed roots (10 out of 12) and expression was always observed in the region of the central stele and in the regions where lateral roots developed (Fig. 1C). In some experiments GUS activity was also detected in the tips of both primary and lateral roots. GUS activity was specifically detected in cells between the phloem and the xylem (Fig. 1D). No GUS activity was detectable in the layer of the pericycle surrounding the vascular tissue, as anticipated from early work done on ENOD40 expression in soybean (Kouchi and Hata 1993). Likewise, for the $\mathrm{p} E N O D 2(B)-g u s A-$ int fusion, $83 \%$ of the root clones analyzed (5 out of 6 ) showed GUS activity. Although less intense, the pattern of GUS activity resembled that obtained with the ENOD4O promoter (data not shown). Finally, the plbc3-gusA-int construct showed GUS activity only in $12 \%$ of the explants. These few stained transformants were probably due to position effect. Consistent with this prediction, the pattern of GUS activity was different in each of the positive clones.

Based on these results we concluded that tagging events into nodule and lateral root morphogenesis genes can be represented among the collection of GUS-positive root explants obtained after transformation with a gusA promoter-less construct.

\section{Nodulation of rol genes-containing plants.}

We assayed L. japonicus transgenic plants for their nodulation capacity to test whether the presence of rol genes perturbed processes involved in symbiosis and in particular the pattern of expression of known nodulin genes. This is particularly important when screening for nodulation-related expression in primary transgenic material. This analysis was first performed in composite plants obtained after infection of L. japonicus seedlings with strain MSU440 carrying construct $\mathrm{p} E N O D 40(2)$-gusA-int. Twelve to 16 days after the infection with MSU440 the transgenic emerging roots were elongated to the extent that the wild-type roots could be excised. The resultant composite plants were transferred to fresh nitrogenfree nodulation medium and inoculated with M. loti NZP2235. Eight days after inoculation, the first emerging nodules were visible and 2 weeks later $90 \%$ of the composite plants showed between 2 and 6 pink nodules. Wild-type plants inoculated under the same conditions gave the same nodulation pattern. In addition, at all developmental stages the morphology of transgenic and wild-type nodules at a macroscopic level was identical. Transgenic roots were stained with 5-bromo-4chloro-3-indolyl- $\beta$-D-glucuronic acid (X-gluc) and nodules were hand sectioned. GUS activity was detectable in nodule primordia or mature nodules of independently transformed roots; no activity was observed in the central stele or regions of secondary root emergence (Fig. 2A). In mature nodules GUS activity was localized to pericycle cells surrounding the vascular bundle as well as in the periphery of the nodule meristem (Fig. 2B), as previously reported for soybean nodules by in situ hybridization (Kouchi and Hata 1993). Similar results were obtained with primary transformants obtained with the same construct. Regenerated shoots with one or more 1- to $1.5-\mathrm{cm}$ long roots were inoculated with $M$. loti and transferred to growth pouches that were irrigated with Jensen's medium supplied with $2 \mathrm{mM} \mathrm{KNO}$. The frequency of successful inoculation of these plants was $70 \%$, despite a history of about 4.5 months in tissue culture conditions. The kinetics of nodule appearance were also quite delayed (about 20 days post inoculation), compared with wild-type plants. Nevertheless, the number of pink nodules per plant in successful infections was the same as with the composite and wild-type plants. The 

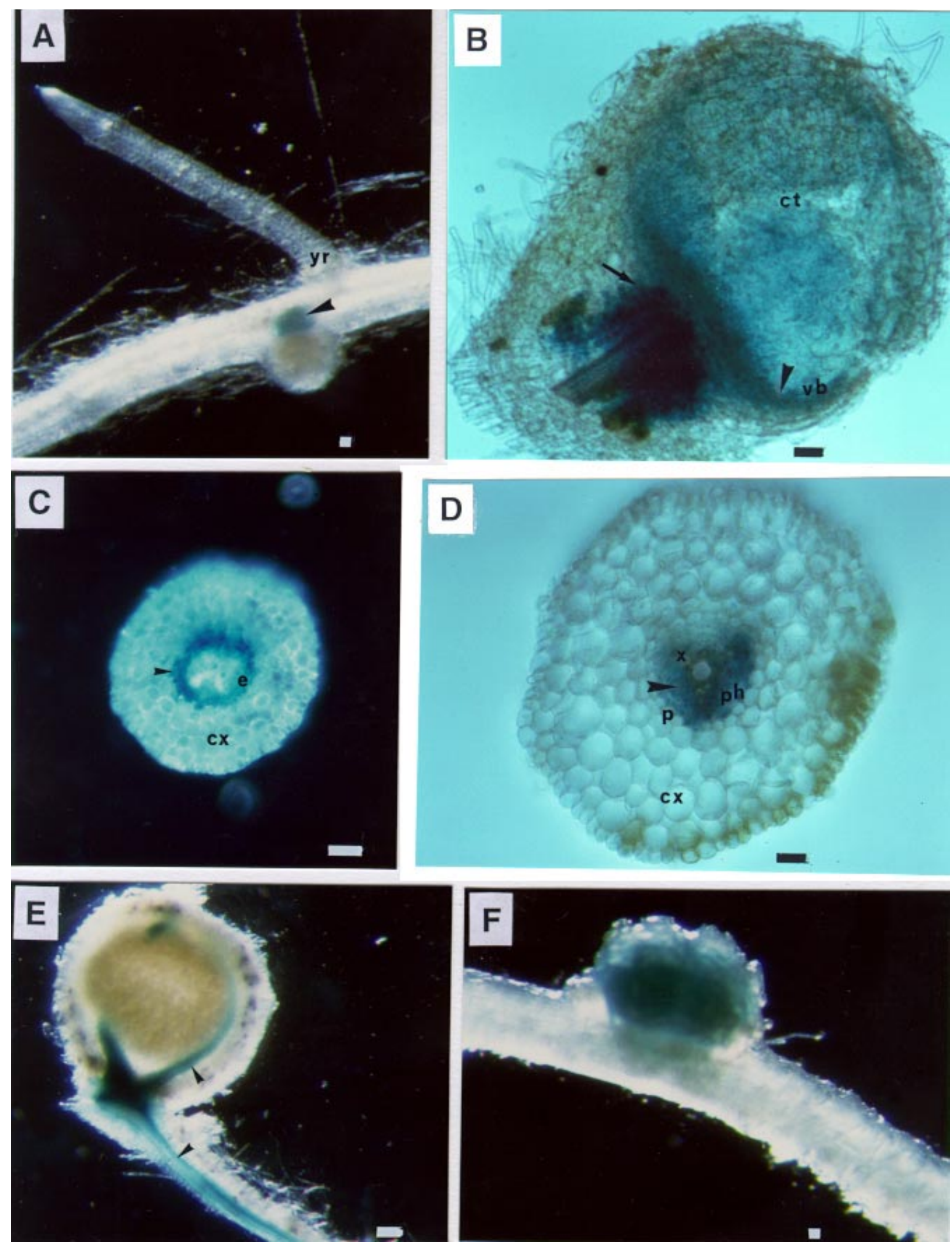
pattern of expression of $\mathrm{pENOD} 40(2)$ in different independent transformants was similar to that obtained with composite plants. No GUS activity was detectable in the lateral root emergence zone and central stele, while strong expression was found in nodule primordia and mature nodules. Thus, the transgenic root system of transformed L. japonicus plants seems to be suitable for the analysis of nodulation- and lateral root-related promoters.

\section{Analysis of single root explant clones.}

Root regions including the microcallus with emerging roots were transferred to MS/2 medium to allow the elongation of single roots. Once these were 1 to $3 \mathrm{~cm}$ long, they were subcultured as single root clones. We were able to recover up to 10 independent roots from a single wound site. To demonstrate the potential of our experimental system we checked how many root meristems recovered from a single wound site represented different integration events (presumably at different loci). To address this question, Southern blot analysis of border fragments from T-DNA integration loci was performed on DNA extracted from different root clones originating from the same wound site. A number of discrete, differently sized fragments, reflecting different loci of integration, were visualized (data not shown). The result was consistent with the pattern of GUS expression observed at the wound site after infection with the Agrobacterium strain carrying p35S-gusAint, where different separated foci of blue staining were detectable (Fig. 1A, B).

\section{Enrichment for integration events into root-expressed genes.}

The described root transformation procedure was set up to obtain a potential enrichment for integration events into rootexpressed genes, assuming that there is a preferential integration of the T-DNA into actively transcribed sequences. If this assumption was correct, then a further enrichment for tagging events into genes involved in the plant response to Mesorhizobium spp. could be obtained with a preliminary inoculation of the L. japonicus seedlings with $M$. loti. For this reason, preinoculation on 4-day-old L. japonicus seedlings was included in the A. rhizogenes transformation protocol. After M. loti inoculation, seedlings were transferred to nitrogen-free nodulation medium and 2 days later infected with the $A$. rhizogenes strain. This variation in the protocol did not affect the effi-

Fig. 2. Histochemical analysis of GUS ( $\beta$-glucuronidase) activity in transgenic Lotus japonicus nodules transformed with the (A and $\mathbf{B}) p E$ NOD4O(2)-gusA-int and (C-F) pGHMC8 constructs. A, GUS activity is revealed at the base of the transgenic young nodule, in the pericycle of the root stele (arrowhead). No GUS activity is detected in the stele of the root system and in the zone of emergence of secondary roots. B, Longitudinal section of the mature nodule showing strong GUS activity in the vascular bundle branching around the central tissue (arrowhead) and in the root pericycle facing the nodule (arrow). C, $L j$-G-7 clone, root cross section showing GUS activity in the endodermis cell layer (arrowhead). D, $L j$-G-21 clone, root cross section showing GUS activity in the vascular cylinder (arrowhead). E, $L j$-G-21 clone, longitudinal section of the nodule and root tissue showing GUS activity in the vascular cylinders of both organs (arrowhead). F, $L j$-G-59 clone, GUS activity in a mature bilobular nodule. Abbreviations: ct, central tissue; cx, cortex; e, endodermis; p, pericycle; ph, phloem; vb, vascular bundles; $x$, xylem; yr, young lateral root. ciency of transformation. A T-DNA binary vector (pGHMC8) was constructed in which the gusA promoter-less cassette was adjacent to the right border (Fig. 3). This T-DNA construct was transferred to strain MSU440( $\operatorname{codA})$ (Stiller et al. 1997) and used for promoter trapping. A collection of 1,270 transgenic roots was obtained; polymerase chain reaction (PCR) analysis on DNA extracted from 100 independent clones confirmed a frequency of $75 \%$ co-transformation events of the pGHMC8 and the Ri-born T-DNAs (952 co-transformed roots). The screening for GUS activity was performed, by histochemical staining, on root explants obtained in four different transformation experiments and grown on MS/2 medium. Root-expressed, GUS-positive fusions were obtained at a frequency ranging from 17 to $28 \%$ in independent experiments (Table 1); a final collection of 220 GUS-positive (23\% of co-transformed roots) clones was produced.

The most common expression pattern was constitutive $(41 \%)$ while $24 \%$ of the transformants expressed GUS only in the stele. A combination of stele, lateral root emergence, and apical meristem expression accounted for $16 \%$ (Table 2). Expression only in the apical meristem was rare, being found in only $4 \%$ of all roots.

To demonstrate that this frequency was related to "inoculated root transformation" and, as postulated, to the particular subset of plant genes transcribed in that root tissue, we performed parallel experiments by transformation of hypocotyl tissue. Presumably, this $M$. loti-free tissue would express fewer root- or nodule-related genes and one would presume that fewer tagging events in such genes would be detected. Obviously the most direct control would have been the use of $M$. loti-free root explants for transformation, but this experiment was not carried out to test for an enrichment

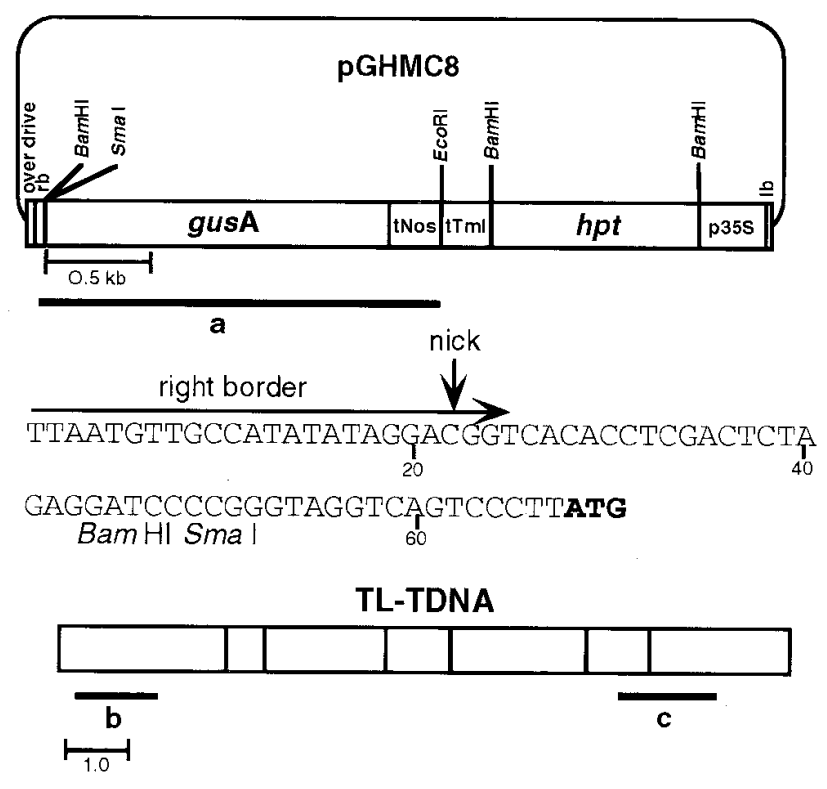

Fig. 3. Schematic representation of the T-region of pGHMC8 and TL TDNA of pRiA4. The junction sequence in pGHMC8 between the right border (with the indication of the nick site) and the ATG of the gusA (indicated in bold) is reported. HindIII sites are indicated in the restriction map of the TL-region of pRiA4. Black bars a, b, and c indicate probes used in Southern blot analysis. Abbreviations: hpt, hygromycin; $\mathrm{lb}$, left border; rb, right border. 
of root-related gene tagging events as well (i.e., inoculated vs uninoculated explants would screen for only a small difference of tissue-specific gene expression).

Composite plants were obtained after transformation with strain MSU440 containing the pGHMC8 construct; histochemical analysis was performed on such transformed roots. The frequency of co-transformation obtained with MSU440 by the hypocotyl transformation procedure was about $70 \%$ (Stiller et al. 1997). The frequency of GUS-positive roots obtained was lower (9 to $15 \%$ of co-transformed roots) compared with each of the root transformation experiments (Table $1)$. These differences between root and hypocotyl transformation procedures were statistically significant $(P<0.001)$.

\section{Molecular analysis of GUS-positive transformants.}

To analyze the frequency of co-integration events of the pRi-born and pGHMC8 T-DNAs at a single locus, we performed Southern blot analysis on eight independent transformants to see whether they shared common border fragments. The DNA was digested with HindIII that does not cut in the pGHMC8 T-DNA whereas it cuts several times in the TL fragment of the pRiA4, and hybridized with the probes $a, b$, and $\mathrm{c}$ shown in Figure 3. A number of discrete bands representing junction fragments including both right and left borders of the pGHMC8 and pRiA4 TL T-DNAs were obtained (Fig. 4). The bands that appear in Figure 4A reflect the TDNA copy number distribution in the eight transformants analyzed; the same distribution (37\% 1 copy, 25\% 2 copies, and $37 \%$ more than 2 copies) was observed on a larger sample of 50 transformants (data not shown). The two bands of about $3.2 \mathrm{~kb}$ in lanes 7 and 8 were smaller than that expected for the size of the T-DNA binary vector $(4.2 \mathrm{~kb})$ and were probably due to degradation of T-DNA ends. However, the observed frequency ( 2 out of the 18 integration events shown in Figure

Table 1. Frequency of root-expressed transcriptional fusions in the root transformation versus the hypocotyl transformation protocols

\begin{tabular}{|c|c|c|c|c|c|c|c|c|}
\hline \multirow{4}{*}{$\begin{array}{l}\text { Transgenic } \\
\text { roots }\end{array}$} & \multicolumn{8}{|c|}{ Transformation } \\
\hline & \multicolumn{5}{|c|}{ Root } & \multicolumn{3}{|c|}{ Hypocotyl } \\
\hline & \multicolumn{4}{|c|}{ Experiment } & \multirow[b]{2}{*}{ Total } & \multicolumn{2}{|c|}{ Experiment } & \multirow[b]{2}{*}{ Total } \\
\hline & 1 & 2 & 3 & 4 & & 1 & 2 & \\
\hline Roots obtained & 252 & 341 & 261 & 416 & 1,270 & 174 & 395 & 569 \\
\hline $\begin{array}{l}\text { Co-transformed } \\
\text { roots }^{\mathrm{a}}\end{array}$ & 189 & 256 & 195 & 312 & 952 & 122 & 276 & 398 \\
\hline $\mathrm{GUS}^{+}$roots (no.) & 54 & 65 & 46 & 55 & 220 & 12 & 41 & 53 \\
\hline $\mathrm{GUS}^{+}$roots $(\%)$ & 28 & 25 & 23.6 & 17.6 & 23.5 & 9.8 & 14.8 & 13.3 \\
\hline
\end{tabular}

${ }^{\text {a }}$ Co-transformation frequency determined by calculation on the basis of the experiments described in this work and in Stiller et al. (1997).

Table 2. Patterns of expression in $\mathrm{GUS}^{+}(\beta$-glucuronidase) transgenic roots of Lotus japonicus

\begin{tabular}{lc}
\hline Root region & $\begin{array}{c}\text { Roots showing } \\
\text { GUS pattern }(\%)^{\mathbf{a}}\end{array}$ \\
\hline Constitutive & 41 \\
Stele and lateral root emergence & 8 \\
Stele, lateral root emergence and meristem & 16 \\
Meristem & 4 \\
Stele & 24 \\
Stele and cortex & 7 \\
\hline
\end{tabular}

${ }^{a}$ Staining was conducted twice for each root clone.
4A) did not significantly change the potential of the mutagenesis approach and, in addition, this rearrangement didn't necessarily affect the expression of the gusA marker. Other diagnostic digestions with restriction sites internal to the pGHMC8 T-DNA did not reveal any other rearrangement in the structure of the integrated copies (data not shown).

The comparison of Figure 4A, B, and C, although complicated by the range of high-molecular-weight fragments being analyzed, revealed a number of common bands that could in-

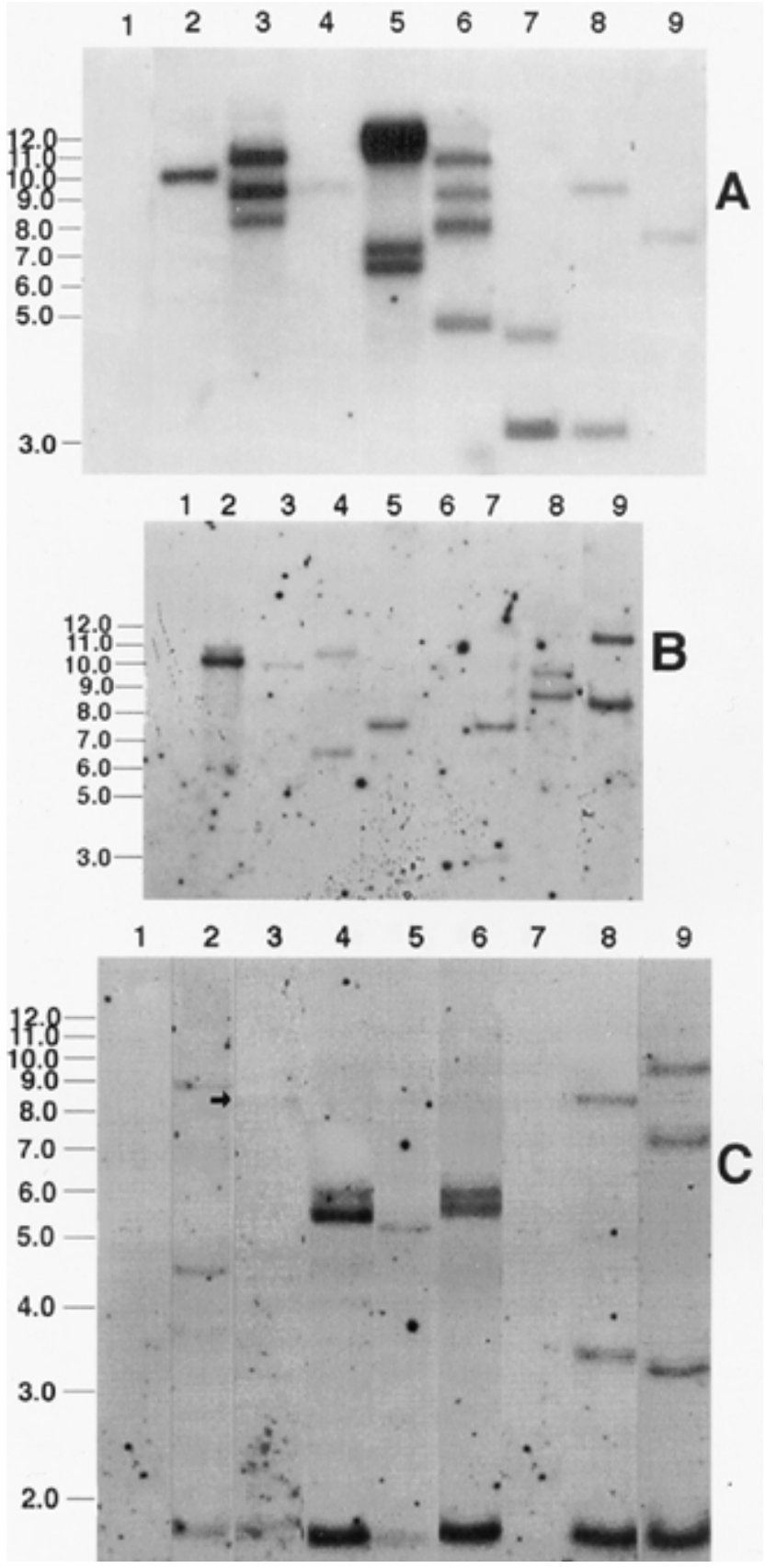

Fig. 4. Molecular analysis of 8 independent regenerants. Southern blot analysis of eight independent GUS ( $\beta$-glucuronidase)-positive regenerants digested with HindIII. Lane 1: wild-type control; lanes 2-9: regenerants. A, Blot analyzed with probe a. B, Parallel blot analyzed with probe b. C, Parallel blot analyzed with probe c. An arrowhead in lane 3 indicates a faint band that was clear after longer exposure of the filter. Size markers are indicated in kilobases. 
dicate co-integration events of the $\mathrm{pRi}$ born (TL) and pGHMC8 T-DNAs $(10,7.5$, and $9.5 \mathrm{~kb}$ in lanes 2,5 , and 8 of Figure $4 \mathrm{~A}$ and $\mathrm{B}$ ).

The 1.8-kb fragment obtained with probe c (Fig. 4C) corresponded to the TL internal HindIII fragment 38 as designated by Pomponi et al. (1983). In 50\% of the transformants analyzed, the number of TL border fragments detected after hybridization with probes $\mathrm{b}$ and $\mathrm{c}$ was not equal (compare lanes 2, 6, 7, and 9 of Figure 4B and C), and in two cases border fragments were not detected at all (lanes 6 and 7 in Figure 4B and $\mathrm{C}$, respectively). This was probably due to large rearrangements and deletions of the TL T-DNA ends (Webb et al. 1994).

\section{Analysis of GUS activity in regenerated plants inoculated with $M$. loti.}

The whole collection of GUS-positive root explants is in the regeneration process and some of these regenerants have been analyzed for GUS activity after inoculation of rooted shoots with M. loti (Table 3). Primarily, this analysis never revealed a mosaic pattern of blue staining, confirming that each isolated root line is a clone. Consistent with the results obtained from studies on root explants, GUS activity was detected in the root tissue (Table 3). Localization and intensity of staining in the different regions of the root system was in general conserved. Some differences in the pattern of GUS expression between root explants and regenerated plants reflect changes in regulation due to the presence of shoots (and associated translocated materials). Cross sections (Fig. 2C and D) showed that the GUS activity detected in the vascular cylinder of the $L j-\mathrm{G} 7$ and $L j$-G21 clones was localized in different cell layers, indicating that with this T-DNA tagging approach a variety of root-expressed genes can be identified. In clone $L j-\mathrm{G} 21$, the fusion seemed to identify a "nodule housekeeping gene." Longitudinal sections (Fig. 2E) showed GUS activity in the vascular cylinder of the root and the nodule and a continuity between the revealed blue staining. This continuity was not observed with clone $L j$-G47, which expressed GUS only in the root vascular cylinder, and $L j-\mathrm{G} 284$, where GUS activity was strongly induced only in the lateral root emergence zone and in the apical meristem (Table 3). In the clone $L j$-G30,

Table 3. GUS ( $\beta$-glucuronidase) activity patterns of regenerants and primary root explants ${ }^{\mathrm{a}}$

\begin{tabular}{|c|c|c|c|c|c|c|c|c|c|c|}
\hline \multirow[b]{3}{*}{ Clones } & \multicolumn{10}{|c|}{ Localization of GUS activity } \\
\hline & \multicolumn{4}{|c|}{ Root explants } & \multicolumn{6}{|c|}{ Regenerants } \\
\hline & ST & LRE & $\mathbf{A M}$ & $\mathbf{C X}$ & ST & LRE & $\mathbf{A M}$ & CX & SNL & NL \\
\hline$j$-G7 & + & ++++ & + & - & ri & ++++ & + & + & + & ++++ \\
\hline i-C & + & +++ & + & - & +++ & +++ & + & - & + & +++ \\
\hline i-G30 & + & +++ & ++ & - & ++ & ++++ & ++ & - & ++ & ++++ \\
\hline$L j-\mathrm{G} 47$ & + & +++ & + & - & + & ++ & + & - & + & - \\
\hline$L j-\mathrm{G} 59$ & +++ & +++ & ++ & + & + & - & - & - & + & ++++ \\
\hline$j-G$ & + & + & + & + & + & - & - & - & + & NT \\
\hline$j-\mathrm{G} 121$ & ++ & ++ & ++ & ++ & ++ & +++ & - & - & + & - \\
\hline$L j-\mathrm{G} 191$ & + & + & + & + & ++ & - & - & - & - & ++++ \\
\hline$L j-\mathrm{G} 284$ & ++ & - & +++ & - & + & +++ & +++ & - & - & - \\
\hline$L j-\mathrm{G} 295$ & ++ & +++ & ++ & - & ++ & +++ & ++ & - & + & NT \\
\hline$L j \mathrm{G} 330$ & + & - & ++ & - & ++ & - & ++ & - & NT & ++++ \\
\hline
\end{tabular}

a Intensity of blue staining is indicated by $+;-$ indicates no detectable signal. Abbreviations: AM: apical meristem; CX: cortex; LRE: lateral root emergence; NL: mature nodule; NT: not tested; SNL: stem and leaves; ST: stele.
GUS activity was slightly induced in nodular tissue as well as in lateral root emergence zones (Table 3 ), while in the $L j$ G191 $L j$-G330 and $L j$-G59 clones the activity was induced at different levels only in the nodule (Fig. 2F and Table 3).

\section{DISCUSSION}

We describe a new experimental scheme for the establishment of T-DNA tagging combined with gene fusion in the model legume $L$. japonicus. The frequency of transformation is a crucial parameter for the success of a T-DNA tagging program and the $A$. rhizogenes transformation procedure described here allows the production of a large number of transgenic roots. The number of hairy roots obtained per wound site (up to 10) is higher than the number obtained with the hypocotyl or epicotyl infection procedures (about 3 to 5; Quandt et al. 1993). Thus, the ease and reliability of this transformation procedure also make it valuable as a hairy root shortcut system, as an alternative to the hypocotyl and epicotyl transformation protocols.

Integration of T-DNA is known to occur preferentially in transcribed regions of the nuclear genome (Koncz et al. 1989). Recent observations suggest that this step might be correlated with a plant-catalyzed repair of DNA damage such as singlestrand nicks or double-strand breaks (Sonti et al. 1995). Since ongoing transcription might lead to DNA damage (Petes et al. 1991), integration in actively transcribed loci would be more frequent. The optimized protocol for transformation of primary roots of L. japonicus was designed to exploit this possible preference for integration into genes that are transcribed in roots, including nodule "housekeeping" genes and nodule- or lateral root-related genes. The difference in the frequency of GUS-positive fusions expressed in roots, obtained after transformation of roots and hypocotyl tissues (23 versus $12 \%$, respectively; Table 1) is statistically significant. Gene expression in plants is known to be strikingly regulated and only a minor fraction of the total mRNAs (about 12\%) are ubiquitous (Kamalay and Goldberg 1980). The mRNA subset present in each organ is only partially overlapping with the one present in other organs. The results shown in Table 1 indicate that TDNA integration occurs preferentially in actively transcribed sequences, suggesting that different transformation protocols of different tissues can be exploited to increase the frequency of tagging events in organ-specific genes. Moreover, prior infection with $M$. loti to induce expression of nodule-related genes might further improve the possibility of an integration event in this class of genes.

In the described procedure, an initial screening for detection of GUS-positive transformants was performed on root explants. These can be cultured in axenic conditions, providing abundant material for screening and identification of clones showing even low level of staining. A collection of 220 GUSpositive lines has been obtained and the analysis of expression permits their classification in different groups with activity located in different root regions. The variation in the pattern of expression of individual transformants clearly suggests that different types of plant genes (or promoters) have been tagged.

We have demonstrated that the two early nodulin promoter fusions $\mathrm{p} E N O D 2(B)$ - $g u s A$-int and $\mathrm{p} E N O D 4 O(2)$ - $g u s A$-int are actively expressed in uninoculated, transgenic root explants 
grown on MS/2 medium (Fig. 1C and D). A disturbed hormonal balance due to either the expression of rol genes or the absence of putative shoot-derived factor(s), or both, could be responsible for such expression. It is possible that in the whole plant a shoot-derived factor(s) silences the expression of these nodulin promoters (note that we defined nodulin genes as genes whose expression is increased in nodules; their expression by no means is considered to be nodule specific). Consistent with this possibility is our analysis of composite and regenerated plants transformed with the pENOD4O(2)-gusAint fusion, which show induced GUS activity only in the nodular tissue (Fig. 2A and B). This result also indicates that the pattern of the $\mathrm{pENOD4O}(2)$ expression is not affected by the presence of the rol genes. A portion of the plant genetic pool that is induced on roots by Rhizobium spp. or Nod factors (Lerouge et al. 1990) comprises genes that are also expressed, albeit at low levels, in roots as well as other plant tissues, without induction. A non-nodular ENOD40 expression was detected in different legumes (Kouchi and Hata 1993; Asad et al. 1994; Flemetakis et al. 1997; Fang and Hirsch 1998).

The screening of the transformant clones is completed on radicated shoots where the presence of the rol genes should not bias the results, as indicated by the conserved pattern of the $\mathrm{pENOD4O(2)}$ in composite and transformed plants (Fig. 2A and B) and by other reported data (Stougaard et al. 1986; Vijn et al. 1995; Roussis et al. 1995). However, the analysis of the T2 segregants and the isolation of the integration loci is in progress, to verify that the gusA promoter-less T-DNA has really tagged root- or nodule-expressed genes.

The analysis reported in Table 3 shows that in all the regenerants tested the expression pattern observed in root explants corresponds to the one in the roots of the primary transformants, indicating that it reflected a physiological regulation of genes expressed in roots. In $80 \%$ of the regenerants analyzed (8 out of 10), GUS expression was observed in root and other organs, while $25 \%$ of the plants showed GUS activity only in root tissues.

The screening of primary transformants is aimed at the isolation of plants showing induced GUS activity in response to Mesorhizobium spp. The observed frequency of gusA noduleinduced fusion is considerably higher and could be due to the success of the enrichment procedure described above. In particular, the clone $L j$-G59 shows strong induction of GUS expression in nodular tissue (Fig. 2F). In this clone there is a clear change in the pattern of GUS expression between root explants and transgenic plants that resembles the shift observed for promoter activity of the GmENOD4O(2) gene.

Obviously, in the identification of mutated phenotypes due to T-DNA tagging events, multiple copy inserts make this analysis more complicated. Nevertheless, the distribution for T-DNA copy number (Fig. 4A), namely, 37\% 1 copy, 25\% 2 copies, and $37 \%$ more than 2 copies, is similar to that obtained in T-DNA tagging programs established in A. thaliana that allowed the isolation of developmentally regulated tagged lines, and identification of several new genes and some related mutated phenotypes.

Studies on progenies of hairy root transformants produced in various species have shown both linked and unlinked segregation patterns of the Ri and binary vector T-DNAs (Visser et al. 1989; Webb et al. 1994). The molecular analysis of the primary transformants indicates that cointegration events be- tween the TL T-DNA carrying the rol genes and the pGHMC8 T-DNA, as expected, are present in our collection of transformants. In particular, in three out of eight plants analyzed (Fig. $4 \mathrm{~A}$ and $\mathrm{B}$, lanes 2, 5, and 8), a set of similar bands that might reflect common flanking fragments is visualized. A possible effect of a co-integration event could be the activation of gus $A$ expression, because of the vicinity of Ri-T-DNA promoters. This kind of event (as a general effect of the rol gene expression on the frequency of the gusA marker activation) should occur at the same frequency independently of the target tissue, and hence would be inconsistent with the observed significant differences in the frequency of GUS-positive clones derived from root- and hypocotyl-transformed tissues. Furthermore, the three plants showing putative common flanking fragments have completely different patterns of GUS expression, ruling out the possibility that in these plants a conserved pattern of co-integration is causing the GUS expression.

The symbiotic phenotype of the transgenic plants will be analyzed after selfing of primary transformants. Backcrosses with wild-type plants can be used to obtain high frequency of T2 segregants that do not carry the pRi TL T-DNA. A direct selection for these segregants can be done with 5-fluorocytosine (5-FC), because strain MSU440, utilized here, carries the negatively selectable marker $\operatorname{cod} A$ (cytosine deaminase; Stiller et al. 1997). The expression of this marker makes the transgenic plants sensitive to 5-FC and enables efficient negative selection in L. japonicus at the seedling level (Stougaard 1993).

The described approach, not being based on the direct analysis of mutant phenotypes, should avoid the isolation of mutants that are not due to integration but arise due to somaclonal variation. Furthermore, in our experimental system plant genes can be identified even if they either do not show any symbiosis- or lateral root-related phenotype, or have a lethal phenotype when mutated. Tagged lines are of immense value for further developmental as well as physiological studies and promise to provide additional information if crossed to other mutant lines such as har-1 (Szczyglowski et al. 1998).

\section{MATERIAL AND METHODS}

\section{Bacterial strains.}

The bacterial strains used are listed in Table 4. A. rhizogenes strains were grown at $28^{\circ} \mathrm{C}$ on LB (Luria-Bertani) medium. M. loti NZP2235 was grown on RMM (Hooykaas et al. 1977) supplied with $\mathrm{KNO}_{3}(1 \mathrm{mg} / \mathrm{ml})$.

\section{Plasmid constructions and DNA analysis.}

pGHMC8 construction (Fig. 3): the EcoRI hygromycin cassette p35S-hpt-tml from pTRA151 (Zheng et al. 1991) was cloned into the EcoRI site of the gusA promoterless pBI101.2 binary vector (Clontech, Palo Alto, CA) to give pGHMC6. The 3.9-kb Sall-HindIII fragment from pGHMC6 was filled in with the Klenow fragment of DNA polymerase and blunt-endligated into the SacI site of pMC1 (Chiurazzi and Signer 1994), likewise filled in with T4 polymerase, to give pGHMC7. PMC1 is a T-DNA vector in which the SacI cloning site is located very close to the molecular termini, $27 \mathrm{bp}$ from the Left Border (LB) end and $9 \mathrm{bp}$ from the Right Border (RB) end. Finally, a 4.2-kb pGHMC7 HindIII fragment, including overdrive sequence, T-DNA borders, GUS-NOS-ter, 
and $h p t$ cassette, was ligated into the HindIII site of pRK404 (Ditta et al. 1985), creating pGHMC8.

Extraction of genomic DNA was carried out according to Della Porta et al. (1983). DNA samples $(7 \mu \mathrm{g})$ were electrophoresed on a $0.8 \%$ agarose gel and transferred to Hybond ${ }^{+}$ nylon (Amersham, Buckinghamshire, UK). The blots were hybridized with ${ }^{32} \mathrm{P}$-labeled probes (Ready To Go, Amersham). Hybridizations were carried out in $50 \mathrm{mM} \mathrm{NaPO}, 5 \%$ SDS (sodium dodecyl sulfate) and $10 \mathrm{mM}$ EDTA at $65^{\circ} \mathrm{C}$. The filters were washed in $0.1 \times$ hybridization solution at $65^{\circ} \mathrm{C}$.

PCR conditions and primer sequences for the estimation of the co-transformation frequency are described in Stiller et al. (1997).

\section{Wound site infection and in vitro culture of roots.}

Surface-sterilized seeds were germinated and grown on $1 \%$ agar plates. Four-day-old seedlings were transferred to nitrogen-free nodulation medium (Jensen medium) and inoculated with $M$. loti. Six-day-old seedlings were cut in the root hair emergence zone at about 0.5 to $1.0 \mathrm{~cm}$ from the growing root tip. The freshly cut surface was inoculated with A. rhizogenes grown overnight in liquid medium. A callus was visible at the wound site 5 days after infection. After 10 days, when microcalli with emerging roots appeared clearly at the wound sites, a piece of the primary root was excised about $3 \mathrm{~mm}$ above the microcallus and transferred to Murashige and Skoog half strength medium (MS/2) containing 3\% sucrose, supplemented with cefotaxime $\left(200 \mu \mathrm{g} \mathrm{ml}^{-1}\right)$ and kept in the dark at $23^{\circ} \mathrm{C}$. After 10 days, well-developed single roots were subcultured.

The regeneration procedure was described in Stiller et al. (1997). A counter selection with cefotaxime sodium salt (Claforan, Lepetit, Milano, Italy) at a concentration of $200 \mu \mathrm{g}$ $\mathrm{ml}^{-1}$ was maintained in tissue culture conditions.

\section{Composite and regenerated plants inoculation.}

Composite plants were transferred to slanted, fresh, nitrogenfree medium agar. Every plant was inoculated with $100 \mu \mathrm{l}$ of a $M$. loti suspension culture grown overnight at $21^{\circ} \mathrm{C}$ with a $16-\mathrm{h}$ photoperiod. The root system was kept in the dark. Primary transformants were inoculated by immersion of the root system in a dense bacterial suspension and then transferred in sterile seed-pack growth pouches and watered with Jensen medium supplied with $2 \mathrm{mM} \mathrm{KNO}_{3}$. Nitrate at this level did not suppress but aided nodulation (A. K. M. Hussain, unpublished). The plants were grown at $21^{\circ} \mathrm{C}$ with a 16 -h photoperiod.

\section{Histochemical GUS analysis.}

Staining was preferentially performed with young tissues cut into pieces not longer than $1.5 \mathrm{~cm}$. Histochemical staining of whole plant material was performed as described by Jefferson (1987). For sections, whole roots were briefly prefixed with $4 \%$ paraformaldehyde, $0.25 \%$ glutaraldehyde in $50 \mathrm{mM}$ $\mathrm{KPO}_{4}$ buffer, $5 \mathrm{mM}$ EGTA, $10 \mathrm{mM}$ DTT (dithiothreitol), $\mathrm{pH}$ 7.2 for $10 \mathrm{~min}$ on ice. Roots were then washed three times with $50 \mathrm{mM} \mathrm{KPO}{ }_{4}$ buffer $\mathrm{pH} 7.2$ and immersed in the staining solution at $37^{\circ} \mathrm{C}$ for various times. After washing, roots were fixed with $4 \%$ paraformaldehyde, $0.25 \%$ glutaraldehyde in 50 $\mathrm{mM} \mathrm{KPO}_{4}$ buffer, $5 \mathrm{mM}$ EGTA, $10 \mathrm{mM}$ DTT, pH 7.2 and stored at $4{ }^{\circ} \mathrm{C}$. Hand-cut sections were analyzed with a light microscope by means of dark- and bright-field optics.

\section{Statistical analysis.}

To compare the frequency of GUS-positive transformants in root- and hypocotyl-transformation procedures, a contingency $\chi^{2}$ test was performed.

\section{ACKNOWLEDGMENTS}

We thank J. Stougaard and T. Bisseling for providing bacterial strains and plasmids and C. Sole for technical assistance. We also thank Ramesh Sonti for useful comments on the manuscript. Work was partially supported by grants from MIRAAF program "Biotecnologie Vegetali," P. S. OLIGONUCLEOTIDI ANTISENSO-CNR, NSF grant "Eukaryotic Genetics" MCB-9808625, the Romanian Government grant 32-4290 (to S. E. R.), and by the Racheff Endowment.

\section{LITERATURE CITED}

Asad, S., Fang, Y., Wycoff, K. L., and Hirsch, A. M. 1994. Isolation and characterization of cDNA and genomic clones of MsENOD40; transcripts are detected in meristematic cells of alfalfa. Protoplasma 183: 10-23.

Beach, K., and Gresshoff, P. M. 1988. Characterization and culture of Agrobacterium rhizogenes transformed roots of forage legumes. Plant Sci. 57:73-81.

Table 4. Bacterial strains and plasmids used in this study

\begin{tabular}{lll}
\hline Strain/plasmid & Relevant characteristic & Origin or source \\
\hline Strains & & \\
Agrobacterium rhizogenes & pRiA4 & \\
MSU440 & codA gene inserted in pRiA4 & Sonti et al. 1995 \\
MSU440(codA) & & Stiller et al. 1997 \\
MSU440-p35SgusA-int & & Stiller et al. 1997 \\
MSU440-GmpENOD40(2)-gusA-int & & This work \\
MSU440-GmpENOD2(B)-gusA-int & & This work \\
MSU440-Gmplbc3-gusA-int & & This work \\
MSU440(codA)-pGHMC8 & Wild-type M. loti & This work \\
Mesorhizobium lot & & \\
NZP2235 & gusA promoter-less and hpt & DSIR culture collection \\
Plasmids & pBIN19 derivative & \\
pGHMC8 & pUC18 derivative, right and left borders & This work \\
p35S-gusA-int & pBI101.2 derivative & Vancanneyt et al. 1990 \\
pMC1 & pIV10 derivative & Chiurazzi and Signer 1994 \\
pENOD40(2)-gusA-int & pBin19 derivative & Roussis et al. 1995 \\
pENOD2(B)-gusA-int & & J. Stougaard \\
plbc3-gusA-int & J. Stougaard \\
\hline
\end{tabular}


Chilton, M. D., Tepfer, D. A., Petit, A., David, C., Casse-Delbart. F., and Tempé, J. 1982. Agrobacterium rhizogenes inserts T-DNA into the genome of host plant root cells. Nature 295:432-434.

Chiurazzi, M., and Signer, E. 1994. Termini and telomeres in T-DNA transformation. Plant Mol. Biol. 26: 923-934.

David, C., Chilton, M. D., and Tempé, J. 1984. Conservation of T-DNA in plants regenerated from hairy root cultures. BioTechnology 2:73-76.

Della Porta, S. L., Wood, J., and Hicks, J. B. 1983. A plant DNA mini preparation: Version II. Plant Mol. Biol. Rep. 1:19-21.

Ditta, G., Schmidhauser, T., Yacobson, E., Lu, P., Liang, X. W., Finlay, D. R., Guiney, D., and Helinski, D. R. 1985. Plasmids related to the broad host range vector, pRK290, useful for gene cloning and monitoring gene expression. Plasmid 13:149-153.

Fang, Y., and Hirsch, A. 1998. Studying early nodulin gene ENOD40 expression and induction by nodulation factor and cytokinin in transgenic alfalfa. Plant Physiol. 116:53-68.

Feldman, K. A. 1991. T-DNA insertion mutagenesis in Arabidopsis: Mutational spectrum. Plant J. 1:71-82.

Flemetakis, M., Kavroulakis, N., and Katinakis, P. 1997. ENOD40 gene in L. japonicus. Are the two different ENOD4O genes differentially expressed? Page 336 in: Biological Nitrogen Fixation for the 21st Century. C. Elmerich, A. Kondorosi, and W. E. Newton, eds. Kluwer Academic Pub., Dordrecht, The Netherlands.

Gresshoff, P. M. 1993. Molecular genetic analysis of nodulation genes in soybean. Plant Breed. Rev. 11:275-318.

Handberg, K., and Stougaard, J. 1992. Lotus japonicus, an autogamous, diploid legume species for classical and molecular genetics. Plant J. 2: 487-496.

Hirsch, A. M. 1992. Developmental biology of legume nodulation. Plant Physiol. 122:211-237.

Hooykaas, P. J. J., Clapwijk, P. M., Nuti, M. P., Shilperoort, R. A., and Roersch, A. 1977. Transfer of the Agrobacterium tumefaciens Ti plasmid to avirulent Agrobacteria and to Rhizobium ex-planta. J. Gen. Mircrobiol. 98:477-484.

Jefferson, R. A. 1987. Assaying chimeric genes in plants: The GUS gene fusion system. Plant Mol. Biol. Rep. 5:387-405.

Jiang, Q., and Gresshoff, P. M. 1997. Classical and molecular genetics of the model legume Lotus japonicus. Mol. Plant-Microbe Interact. 10: 59-68.

Kamalay, J. C., and Goldberg, R. B. 1980. Regulation of structural gene expression in tobacco. Cell 19:935-946.

Kolchinsky, A., Landau-Ellis, D., and Gresshoff, P. M. 1997. Map order and linkage distances of molecular markers close to the supernodulation (nts-1) locus of soybean. Mol. Gen. Genet. 254:29-36.

Koncz, C., Martini, N., Mayerhofer, R., Koncz-Kalman, Z., Korber, H., Redei, G., and Schell, J. 1989. High-frequency T-DNA-mediated gene tagging in plants. Proc. Natl. Acad. Sci. USA 86:8467-8471.

Kouchi, H., and Hata, S. 1993. Isolation and characterization of novel nodulin cDNAs representing genes expressed at early stages of soybean nodule development. Mol. Gen. Genet. 238:106-119.

Lerouge, P., Roche, P., Faucher, C., Maillet, F., Truchet, G., Promé, J. C., and Dénarié, J. 1990. Symbiotic host-specificity of Rhizobium meliloti is determined by a sulphated and acylated glucosamine oligosaccharide signal. Nature 344:781-784.

Long, S. 1996. Rhizobium symbiosis: Nod factors in perspective. Plant Cell 8:1885-1898.

Petes, T. D., Malone, R. E., and Symingtone, L. S. 1991. Pages 407-521 in: The Molecular and Cellular Biology of the Yeast Saccharomyces. J. R. Broach, J. R. Pringle, and E. W. Jones, eds. Cold Spring Harbor Laboratory, Plainview, NY.

Pomponi, M., Spanò, L., Sabbadini, M. G., and Costantino, P. 1983.
Restriction endonuclease mapping of the root-inducing plasmid of Agrobacterium rhizogenes 1855. Plasmid 10:119-129.

Quaedvlieg, N. E. M., Schlaman, H. R. M., Admiraal, P. C., Wijting, S. E., Stougaard, J., and Spaink, H. P. 1998. Fusions between green fluorescent protein and $\beta$-glucuronidase as sensitive and vital bifunctional reporters in plants. Plant Mol. Biol. 37:715-727.

Quandt, H.-J., Pühler, A., and Broer, I. 1993. Transgenic root nodules of Vicia hirsuta: A fast and efficient system for the study of gene expression in indeterminate-type nodules. Mol. Plant-Microbe Interact. 6: 699-706.

Roussis, A., van de Sande, K., Papadopoulou, K., Drenth, J., Bisseling, T., Franssen, H. and Katinakis, P. 1995. Characterization of the soybean gene GmENOD40-2. J. Exp. Bot. 46:719-724.

Sonti, R. V., Chiurazzi, M., Wong, D., Davies, C. S., Harlow, G. R., Mount, D. W., and Signer, E. R. 1995. Arabidopsis mutant deficient in T-DNA integration. Proc. Natl. Acad. Sci. USA 92:11786-11790.

Stiller, J., Martirani, L., Tuppale, S., Chian, R., Chiurazzi, M., and Gresshoff, P. M. 1997. High frequency transformation and regeneration of transgenic plants in the model legume Lotus japonicus. J. Exp. Bot. 48:1357-1365.

Stougaard, J. 1993. Substrate-dependent negative selection in plants using a bacterial cytosine deaminase gne. Plant J. 3:755-761.

Stougaard, J., Marcker, J., Otten, K. A., and Schell, J. 1986. Nodulespecific expression of a chimeric soybean leghaemoglobin gene in transgenic Lotus corniculatus. Nature 321:669-674.

Szczyglowski, K., Hamburger, D., Kapranov, P., and de Bruijn, F. J. 1997. Construction of a Lotus japonicus late nodulin expressed sequence tag library and identification of novel nodule-specific genes. Plant Physiol. 114:1335-1346.

Szczyglowski, K., Shaw, R. S., Wopereis, J., Copeland, S., Hamburger, D., Kasiborski, B., Dazzo, F. B., and de Bruijn, F. J. 1998. Nodule organogenesis and symbiotic mutants of the model legume Lotus japonicus. Mol. Plant-Microbe Interact. 11:684-697.

Thykjaer, T., Stiller, J., Handberg, K., Jones, J., and Stougaard, J. 1995. The maize transposable element $A c$ is mobile in the legume Lotus japonicus. Plant Mol. Biol. 27:981-993.

Topping, J. F., Agyeman, F., Henricot, B., and Lindsey, K. 1994. Identification of molecular markers of embryogenesis in Arabidopsis thaliana by promoter trapping. Plant J. 5:895-903.

Vancanneyt, G., Schmidt, R., O'Connor-Sanchez, A., Willmitzer, L., and Rocha-Sosa, M. 1990. Construction of an intron-containing marker gene: Splicing of the intron in transgenic plants and its use in monitoring early events in Agrobacterium-mediated plant transformation. Mol. Gen. Genet. 220:245-250.

Vijn, I., Christiansen, H., Lauridsen, P., Kardallsky, I., Quandt, H.-J., Drenth, J., Jensen, E. O., van Kammen, A., and Bisseling, T. 1995. A $200 \mathrm{bp}$ region of the pea ENOD12 promoter is sufficient for nodulespecific and nod factor induced expression. Plant Mol. Biol. 28:11031110.

Visser, R. G. F., Hesseling-Meinders, A., Jacobsen, E., Nijdam, H., Witholt, B., and Feenstra, W. J. 1989. Expression and inheritance of inserted markers in binary vector carrying Agrobacterium rhizogenestransformed potato (Solanum tuberosum). Theor. Appl. Genet. 78: 705-714.

Webb, K. J., Robbins, M. P., and Mizen, S. 1994. Expression of GUS in primary transformants and segregation patterns of GUS, TL- and TRDNA in the T1 generation of hairy root transformants of Lotus corniculatus. Transgen. Res. 3:232-240.

Zheng, Z., Hayashimoto, A., Li, Z., and Norimoto, M. 1991. Hygromycin resistance gene cassettes for vector construction and selection of transformed rice protoplasts. Plant Physiol. 97:832-835. 